Indexed by

Scopus

\title{
INVESTIGATION OF THE METHOD OF THERMAL FRICTION TURN-MILLING OF HIGH STRENGTH MATERIALS
}

Crossref
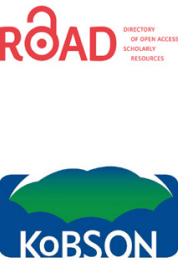

\section{Sabit Magavin}

S. Seifullin Kazakh Agro Technical University, Technical faculty, Nur-Sultan,

Kazakhstan

\author{
Medgat Mussayev \\ Karaganda Technical \\ University, Mechanical \\ Engineering faculty, \\ Karaganda, \\ Kazakhstan
}

\author{
Nazerke Abisheva \\ Karaganda Technical \\ University, Mechanical \\ Engineering faculty, \\ Karaganda, \\ Kazakhstan
}

\author{
Muratbek Usserbayev \\ S. Seifullin Kazakh Agro \\ Technical University, \\ Technical faculty, \\ Nur-Sultan, \\ Kazakhstan
}

\section{Yeldos Bekzhanov}

S. Seifullin Kazakh Agro Technical University, Technical faculty, Nur-Sultan, Kazakhstan

\section{Balgali Myrzakhmet}

S. Seifullin Kazakh Agro Technical University, Technical faculty, Nur-Sultan, Kazakhstan

Key words: thermal friction turn-milling, roughness, hardness, feed motion, braked layer, high strength material

doi:10.5937/jaes0-29546

Cite article:

Sherov K., Mussayev M., Usserbayev M., Magavin S., Abisheva N., Karsakova N., Kuanov I., Bekzhanov Y., Myrzakhmet B. (2022) INVESTIGATION OF THE METHOD OF THERMAL FRICTION TURN-MILLING OF HIGH STRENGTH MATERIALS, Journal of Applied Engineering Science, 20(1), 13 - 18, DOI:10.5937/ jaes0-29546

Online aceess of full paper is available at: www.engineeringscience.rs/browse-issues 


\title{
INVESTIGATION OF THE METHOD OF THERMAL FRICTION TURN-MILLING OF HIGH STRENGTH MATERIALS
}

\author{
Karibek Sherov'*, Medgat Mussayev², Muratbek Usserbayev', Sabit Magavin'1, Nazerke Abisheva², Nurgul \\ Karsakova², Issa Kuanov', Yeldos Bekzhanov', Balgali Myrzakhmet ${ }^{1}$ \\ ${ }^{1}$ S. Seifullin Kazakh Agro Technical University, Technical faculty, Nur-Sultan, Kazakhstan \\ ${ }^{2}$ Karaganda Technical University, Mechanical Engineering faculty, Karaganda, Kazakhstan
}

An analysis of the state of the matter of the manufacture of parts such as bodies of revolution has shown that there is a problem of turning processing by turning large, long parts, connected with increasing productivity and processing quality, as well as reducing the costs of turning operations. To solve this problem, the authors propose a resource-saving combined method for treating external cylindrical surfaces by thermal friction turn-milling. Experimental studies were performed on the processing of the outer cylindrical surface using a special friction cutter made of non-instrumental material. The results showed that with thermal friction turn-milling, it is possible to achieve Ra = $1,0 \mathrm{mcm}$. The process of chip formation was also investigated and the formation of a retarded layer was established, which protects the surface of the friction cutter from wear. Optimum values of cutting conditions for processing by thermal friction turn-milling of steel 30HGSA.

Key words: thermal friction turn-milling, roughness, hardness, feed motion, braked layer, high strength material

\section{INTRODUCTION}

As a result of the research carried out in the conditions of the mechanical engineering enterprises of the Republic of Kazakhstan (RK), in particular, JSC «Almaty Heavy Machinery Plant», LLP «Maker» - KLMZ and LLP «Kurylysmet» Production No. 2 (NOMM plant), it was revealed that there is a problem of turning processing by turning large, long parts related to increasing productivity and processing quality, as well as reducing the costs of turning operations. When turning large-sized long parts of bodies of rotation, one of the main factors affecting the quality and productivity of cutting is the emergence of a hit load on the cutter and the formation of continuous chips of various shapes and sizes.

With the creation of multifunctional lathes equipped with a tool head with its own drive, it became possible to carry out a milling operation that eliminates the mentioned difficulties [1]. However, when using standard face mills equipped with hard-alloy teeth, another problem arises, related to the cost of performing a milling operation. The use of high-performance milling in the conditions of mechanical engineering enterprises of the RK is also hampered by the absence of multifunctional lathes with numerical control.

In the conditions of machine-building enterprises, where mainly universal machine tools are used, this problem is further aggravated. To solve the above problems, the authors in the framework of the grant theme: AP08956387 «Creating a prototype universal device based on a lathe for the implementation of turn-milling technology» was studied the method of thermal friction turn-milling using a special cutting tool - a friction milling cutter [2], [3].

One of the main differences of the developed method is the use of a special friction milling cutter from non-tool material instead of standard face milling cutters. And also, for the implementation of the method of thermal friction turn-milling in the conditions of machine-building enterprises of the Republic of Kazakhstan, on the basis of universal lathes a special device was designed and made.

The study and investigation of the influence of cutting regimes on the quality of the treated surface and the process of chip formation during thermal friction milling have both scientific-theoretical and practical significance. The results of the study may lead to the improvement of the structural elements of the cutting tool, and also will allow to explain and correctly use in practice the strength and stability dependences.

In this regard, the work aimed at investigating the effect of cutting regimes on the quality of the treated surface, as well as the cutting mechanism and the deformed state of the material during processing with thermal friction turn-milling, is an actual task.

The tasks set in the work were solved by experimental and theoretical methods. In theoretical studies, the main provisions of the theory of cutting materials, the theory of plasticity and elasticity, the theory of chip formation, the technology of metals, materials science.

\section{METHODOLOGY AND EQUIPMENT FOR THE STUDY}

The research was carried out using the equipment of the International Materials Science Centre of the Karaganda Technical University. The roughness and hardness of the machined surfaces were measured using electronic devices. Figure 1 shows photographs of electronic instruments for measuring roughness and hardness of treated surfaces. 


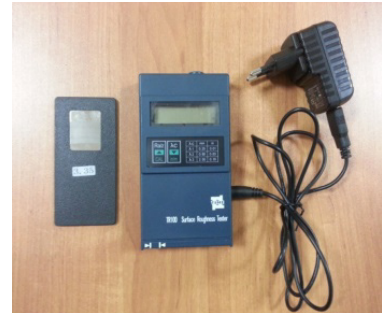

(a)

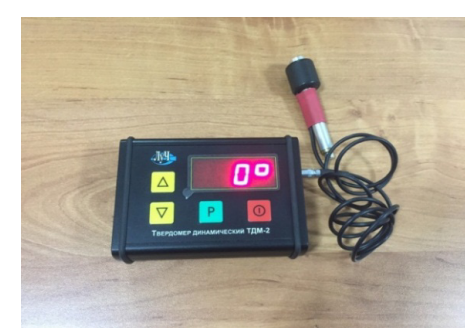

(b)
Figure 1: Photographs of electronic instruments for measuring roughness and hardness of treated surfaces (a - portable meter (profilometer) roughness TR 100; $b$ - compact dynamic hardness tester TDM-2)

To implement the thermal friction turn-milling method, a special lathe-based device was developed and manufactured [4]. The main advantage of the proposed method is the use of a special friction milling cutter from non-tool material instead of standard face milling cutters. Figure 2 shows photographs of a special device and a friction cutter for milling.

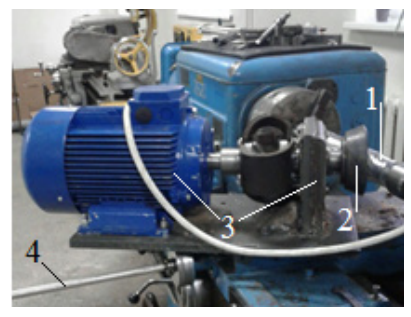

(a)

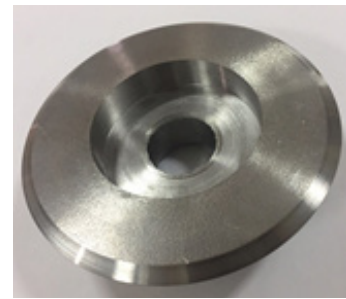

(b)
Figure 2: Photo of a special device for turn-milling (a - device for milling; $b$ - friction cutter; 1 - workpiece; 2

- frictional milling cutter; 3 - the device mounted on the support of the machine; 4 - vertical feed handle)

\section{EXPERIMENT PLANNING}

The planning of the experiment consists of choosing the number and conditions of the experiments, allowing to obtain the necessary knowledge about the research object with the required accuracy.

The most important condition for a scientifically staged experiment is to minimize the number of experiments, and therefore the cost of material, labor, and time re- sources, but this should not significantly affect the quality of the information obtained, the use of experimental planning methods is limited by the complexity or impossibility of setting up an experiment in real conditions [5], [6].

If the analytical dependence linking the response function $(Y)$ with influencing factors $(X i)$ cannot be found, that is, $Y=f$ $\left(\mathrm{X}_{1}, \mathrm{X}_{2}, \ldots, \mathrm{Xi}\right)$, then it is advisable to use a power series:

$$
Y=a_{0}+\sum_{i=1}^{k} a_{i} X_{I}+\sum_{i=1}^{k} a_{i j} X_{i} X_{j}+\sum_{i=1}^{k} a_{i i} X_{i}^{2}+\ldots .
$$

where $\mathrm{k}$ - the number of influencing factors.

Analysis of the available information about the object indicates that linear effects and pair interactions are of the greatest interest. Therefore, the object model looks like:

$Y=a_{0} X_{0}+a_{1} X_{1}+a_{2} X_{2}+a_{3} X_{3}+a_{12} X_{1} X_{2}+a_{13} X_{1} X_{3}+a_{23} X_{2} X_{3}$

The simplest plan, allowing the estimation of all the coefficients of such a model ( $S=7$ is the number of coefficients of the approximating polynomial) is a full-factor experiment of type 23 , where $\mathrm{N}=8$ is the number of experiments. In this case, the number of repetitions of experiments is $m=3$.

The sequence meets the requirements of randomization, i.e. organization of a random sequence of experiments to minimize the influence of interference.

Let's write down the response functions: Influencing factors: $\mathrm{m}=3, \mathrm{~N}=8, \mathrm{~S}=7$

$$
Y_{1}=\left(\begin{array}{l}
9.5 \\
2.6 \\
1.3 \\
1.3 \\
1.0 \\
1.5 \\
5.0 \\
9.8
\end{array}\right) \quad Y_{2}=\left(\begin{array}{c}
7 \\
1.1 \\
1 \\
0.9 \\
1.0 \\
1.2 \\
2.0 \\
6.5
\end{array}\right) \quad Y_{3}=\left(\begin{array}{l}
8.1 \\
1.8 \\
1.1 \\
1.12 \\
1.18 \\
1.3 \\
3.1 \\
6.8
\end{array}\right) \quad X_{0}=\left(\begin{array}{l}
1 \\
1 \\
1 \\
1 \\
1 \\
1 \\
1 \\
1
\end{array}\right) \quad X_{1}=\left(\begin{array}{c}
-1 \\
1 \\
-1 \\
1 \\
-1 \\
1 \\
-1 \\
1
\end{array}\right) \quad X_{2}=\left(\begin{array}{c}
-1 \\
-1 \\
1 \\
1 \\
-1 \\
-1 \\
1 \\
1
\end{array}\right) \quad X_{3}=\left(\begin{array}{c}
-1 \\
-1 \\
-1 \\
-1 \\
1 \\
1 \\
1 \\
1
\end{array}\right)
$$

Response function mean: Reproducibility variance:

$$
Y_{C}=\frac{Y_{1}+Y_{2}+Y_{3}}{3} \quad Y_{C}=\left(\begin{array}{c}
8.2 \\
1.833 \\
1.133 \\
1.107 \\
1.06 \\
1.333 \\
3.367 \\
7.7
\end{array}\right)
$$

Table 1: Input factors

\begin{tabular}{|c|c|c|c|c|c|}
\hline \multirow{2}{*}{$\mathbf{X}_{\mathbf{1}}$} & $\mathbf{X}_{2}$ & \multirow{2}{*}{$\mathbf{X}_{\mathbf{3}}$} & \multicolumn{3}{|c|}{$\mathbf{Y}$} \\
\cline { 4 - 6 } & -1 & -1 & $\mathbf{1}$ & $\mathbf{2}$ & $\mathbf{3}$ \\
\hline-1 & -1 & -1 & 9,5 & 7 & 8.1 \\
\hline 1 & 1 & -1 & 2,6 & 1.1 & 1.8 \\
\hline-1 & 1 & -1 & 1,3 & 1 & 1.1 \\
\hline 1 & -1 & 1 & 1,3 & 0.9 & 1.12 \\
\hline-1 & -1 & 1 & 1 & 1 & 1.18 \\
\hline 1 & 1 & 1 & 1,5 & 1.2 & 1.3 \\
\hline-1 & 1 & 1 & 5 & 2 & 3.1 \\
\hline 1 & & & 9,8 & 6.5 & 6.8 \\
\hline
\end{tabular}


$D y_{i}=\frac{1}{m-1}\left[\left(Y_{1}-Y c\right)^{2}+\left(Y_{2}-Y c\right)^{2}+\left(Y_{3}-Y c\right)^{2}\right] \quad D y_{i}=\left(\begin{array}{c}1.57 \\ 0.563 \\ 0.023 \\ 0.04 \\ 0.011 \\ 0.023 \\ 2.303 \\ 3.33\end{array}\right)$

Definition of Cochran's criterion:

Cochran's criterion is used to assess the accuracy of the experimental error. In this case, the calculated value is compared with the table.

$\max \left(D y_{i}\right)=3.33 \quad \sum D y_{i}=7.864$

$G=\frac{\max \left(D y_{i}\right)}{\sum D y_{i}} \quad G=0,423 \quad G_{t a b}=0,516$

The tabular value of $\mathrm{G}$ with $\mathrm{m}-1=2$ and $\mathrm{N}=8$ is 0,516 . Since $\mathrm{G}=0,423<\mathrm{Gt}=0.516$, the hypothesis of equal accuracy is not rejected, i.e. all experiments were performed with an equal error.

\section{EXPERIMENTAL STUDY AND DISCUSSION FROM RESULTS}

Figure 3 shows photographs of the process of thermal friction turn-milling (a view after finishing the treatment) and an enlarged view of the treated surfaces obtained from various experiments.

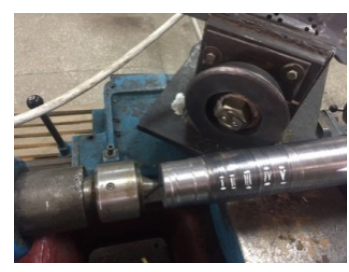

(a)

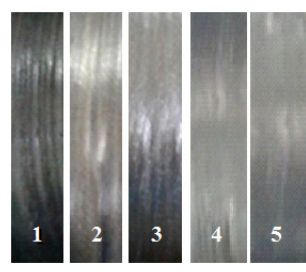

(b)

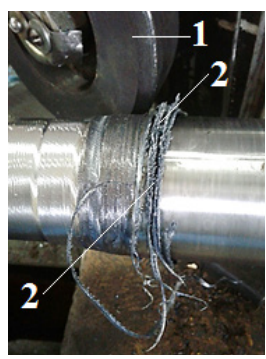

(c)

Figure 3: Photographs of the thermal friction turn-milling process and an enlarged view of the treated surfaces ( $a$ - machining process; $b$ - enlarged view of the treated surfaces obtained from various experiments; $c$ - the formation of chips: (1-friction disc, 2-chip))

There is a workpiece $(\varnothing 80 \mathrm{~mm}, \mathrm{~L}=510 \mathrm{~mm})$ of steel 30HGSA for thermal friction turn-milling. 10 levels of experiment were performed under different treatment regimes.

Table 2 shows the values of the cutting regimes and the quality indices of the treated surface for various experiments.
Figure 4 shows the graphs of the effect of cutting regimes on the roughness and hardness of the treated surface.

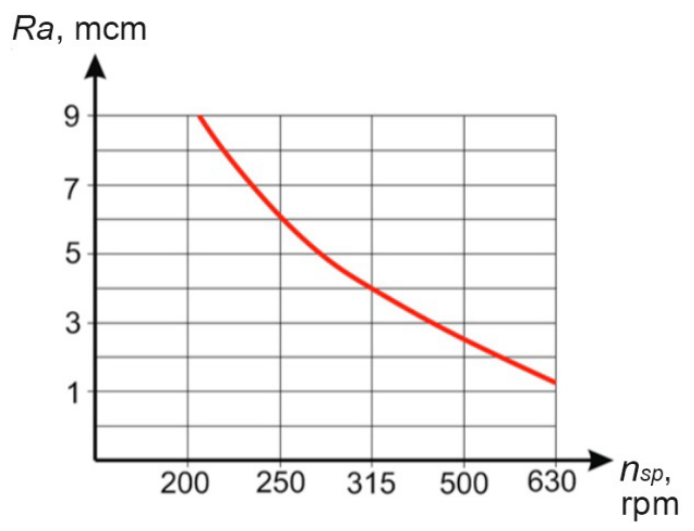

$H B$,

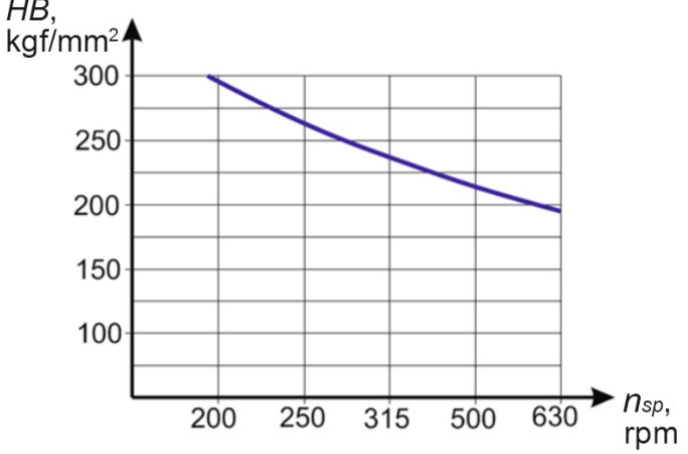

$R a$,

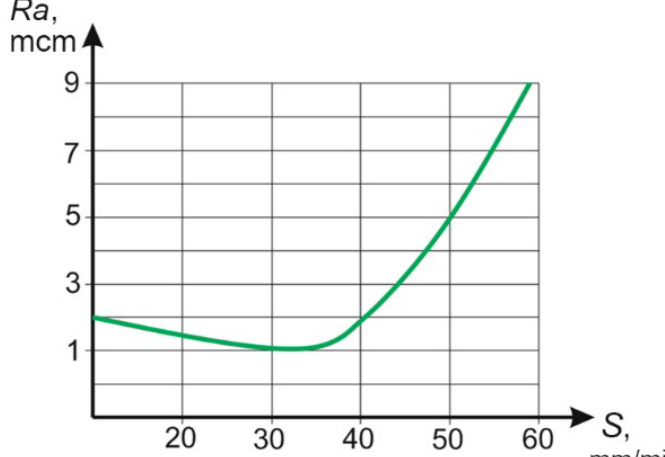

$H B$,

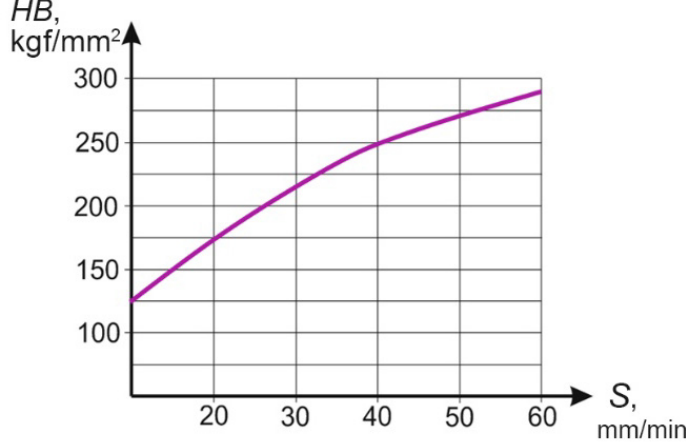

Figure 4: Graphs of the effect of cutting regimes on the roughness and hardness of the treated surface (a - graph of the effect of spindle speed on surface roughness; $b$ - graph of the effect of spindle speed on surface hardness; $c$ - graph of the effect of feed on the surface roughness; $d$-graph of the effect of feed on the hardness of the surface) 
Table 2: Values of cutting modes and quality indicators

\begin{tabular}{|c|c|c|c|c|c|c|}
\hline \multirow{2}{*}{ No } & \multicolumn{3}{|c|}{ Cutting regimes } & \multicolumn{3}{c|}{ Quality of the treated surface } \\
\cline { 2 - 7 } & $n_{s p^{\prime}}, \mathrm{rpm}$ & $n_{\text {tool }}, \mathrm{rpm}$ & $S, \mathrm{~mm} / \mathrm{min}$ & $t, \mathrm{~mm}$ & $R_{a}, \mu \mathrm{m}$ & $H B, \mathrm{~kg} / \mathrm{mm}^{2}$ \\
\hline 1 & 200 & 3000 & 10 & 1,0 & 9,5 & 285 \\
\hline 2 & 250 & 3000 & 10 & 1,0 & 6,0 & 263 \\
\hline 3 & 315 & 3000 & 10 & 1,0 & 4,0 & 243 \\
\hline 4 & 500 & 3000 & 10 & 1,0 & 2,6 & 213 \\
\hline 5 & 630 & 3000 & 10 & 1,0 & 1,2 & 190 \\
\hline 6 & 630 & 3000 & 20 & 1,0 & 1,3 & 175 \\
\hline 7 & 630 & 3000 & 30 & 1,0 & 1,0 & 215 \\
\hline 8 & 630 & 3000 & 40 & 1,0 & 1,5 & 248 \\
\hline 9 & 630 & 3000 & 50 & 1,0 & 5,0 & 274 \\
\hline 10 & 630 & 3000 & 60 & 1,0 & 9,8 & 290 \\
\hline
\end{tabular}

In the experiments No. 1-3 and No. 9-10 (see Table 2), the treated surfaces were rough $(\mathrm{Ra}=9,8 \div 4)$. Arsons were also formed in places (see Fig. 3b, 1 and 3). In the experiments No. 4-5 and No. 6-8 (see Table 2), the roughness of the treated surfaces (see Fig. 3b, 4 and 5 ) was improved $(\mathrm{Ra}=2,6 \div 1,0)$. The optimal cutting regimes correspond to experiment No. 7 (see Table 2). From the graph (see Fig. 4a) it can be seen that as the spindle speed increases, the quality of the treated surface improves. And an increase in feed rate leads to a worsening of the roughness. The results of experiments No. 5 and No. 6 (see Table 2) also meet the requirements of quality indicators, in particular, on the roughness and hardness of the treated surfaces. However, we give preference to experiment No. 7 , since here the supply value is high, and the lower feed rate reduces the processing capacity, which is one of the problems of turning. And also, when machining cutting conditions with the corresponding experience No. 7 , the hardness of the treated surface is obtained as close as possible to the maximum hardness (HB 215) for steel 30HGSA. The hardness of steel 30HGSA normalized (thick sheet) according to GOST 11269-76 is HB 156 - 217. For hotrolled rods according to GOST 10702-78 is HB 217.

Processing by traditional cutting of high-strength steels is characterized by extremely low plastic deformation in chip formation [7], [8]. Mechanical work is spent mainly on the elastic deformation and friction of the workpiece being machined on the back surface of the tool. As a rule [9], there is no increase in the processing of these materials. For these reasons, the wear of the tool is very intensive and occurs mainly along the back surface. When processing these materials, because of the high values of the mechanical characteristics, there are large values of the cutting force, which lead to a decrease in tool life. In thermal friction turn-milling, the cutting mechanism is performed in a different way, due to the appearance under certain temperature conditions of the current layer [3], which is in a sufficiently plastic state, close to the recrystallization temperature. The appearance of the current layer leads to a reduction in friction on the surface of the tool-workpiece, therefore, to a decrease in wear and improve the quality of the treated surface.

The main factors determining the possibility of rational processing by cutting high-strength materials are to ensure the maximum possible softening of the material of the cut layer while maintaining a sufficiently high strength and wear resistance of the cutting tool at elevated temperatures, creating high rigidity and vibration resistance of the technological system, and controlling heat fluxes in the contact zone "tool-workpiece» [10], [11].

It is known that carbon steel retains its strength characteristics at temperatures up to $400^{\circ} \mathrm{C}$ [12]. These values for high-speed steels $600^{\circ} \mathrm{C}$, for hard alloys $800^{\circ} \mathrm{C} \div$ $900^{\circ} \mathrm{C}$. The degree of softening of the material of the cut layer continuously increases with increasing temperature. Considering the interaction in the process of cutting tools and workpiece materials, cutting modes and, first of all, the speed is chosen based on the maximum permissible redness of the tool material. The higher the cutting speed and the strength of the material, the greater the temperature in the cutting zone. Of great importance in this case is the degree of temperature equalization over the section of the cut, i.e. The nature of the temperature fields and their intensity in the chip-forming zone.

Increasing the hardness of the processed material increases the amount of heat released during cutting and, therefore, reduces the allowable cutting speed. The process of cutting during thermal friction turn-milling is characterized not only by the high rate of deformation, but also by high strain rates. Since the cutting process with thermo-friction milling takes place under complex thermodynamic conditions, the retarding effect of the cutting tool becomes so large that it results in a tight joining of the part of the chips to the front surface and formation of a retarded layer, which is clearly seen in the obtained micrographs. It is known that a retarded layer is usually formed when cutting plastic and viscous materials [7]. In our case, the main reason for the formation of a retarded layer is the absence of cooling during thermal friction turn-milling.

Istraživanja i projektovanja za privredu ISSN 1451-4117 Journal of Applied Engineering Science Vol. 20, No. 1, 2022 
It should also be noted that in work [3] it was established that when thermal friction turn-milling occurs, the current layer appears, due to which there is a slip of the chips with respect to the current stagnant layer, which protects the surface of the friction cutter from wear. This phenomenon determines the features of thermal friction turn-milling as a process.

For the emergence of the current layer, certain conditions are required, of which the most important and determining is the proper temperature, concentrating in a small boundary layer. Based on the available data [13] - [15], we can assume that the value of this temperature varies within the value of the recrystallization temperature of the material being processed.

The results of experimental experiments have shown that the main conditions for satisfactory processing of thermal friction turn-milling of high-strength steels are to ensure the maximum possible rigidity and vibration resistance of the technological system, careful sharpening of the cutting tool and clean working surfaces. When choosing the optimal machining conditions, this method of milling ensures the same accuracy and roughness of processing as in the case of rough grinding, and at the same time gives a better surface quality, and therefore greater durability and reliability of operation of the manufactured parts.

This is due to the absence of such characteristic defects for grinding as burns, structural transformations, caricaturing of the surface layer by particles of abrasive.

\section{CONCLUSIONS}

The results of a study of the state of the problem of machining and manufacturing of parts in the conditions of machine-building enterprises of the Republic of Kazakhstan showed that there is a problem of turning processing by turning large, long parts, connected with increasing productivity and processing quality, as well as reducing the costs of turning operations.

It was found that when processing high-strength materials, it is not always possible to achieve the processing efficiency, ensuring the required accuracy and quality. The use of more highly efficient processing methods, in particular milling, is also impossible, in view of the absence of an appropriate cutting tool and machine tool.

To solve these problems, a resource-saving technology is proposed for processing parts such as bodies of revolution, made of high-strength materials, thermal friction turn-milling. And also, a universal device for performing thermal friction turn-milling on universal lathes.

It has been experimentally established that with thermal friction turn-milling, it is possible to achieve $\mathrm{Ra}=$ $1.0 \mathrm{mcm}$, which corresponds to black grinding. With this method, there are no defects that are characteristic for grinding, such as burns, structural transformations, caricature of the surface layer by particles of abrasive.

It is revealed that during the process of thermal friction turn-milling, the part of the chips is densely joined to the front surface, which promotes the formation of a retarded layer. Hence it can be concluded that part of the chips is not moving along the tool, but on the braked layer that covers the front surface, keeping it from wear. This phenomenon determines the features of thermal friction turn-milling as a process.

\section{REFERENCES}

1. Selivanov, A.N., Nasad, T.G., Tormanov, S.Y. (2011). Experimental investigations of chip formation during processing of titanium alloy VT 1-0 with the method of high-speed circumferential milling. Bulletin of the CSTU. №2(56). Issue 2.- P.138-144.

2. Sherov, K.T., Sikhimbayev, M.R., Nasad, T.G., Absadykov, B.N., Izotova, A.S., Okimbayeva, A.E., Kuanov, I.S. (2020). The research of the steel cutting blade reliability for thermo-frictional processing. News of the National Academy of Sciences of the Republic of Kazakhstan. Series of geology and technical sciences. Volume 1, Number 439, P.122 - 130. https://doi.org/10.32014/2020.2518-170X.15

3. Sherov, K.T., Mussayev, M.M. (2016). Calculation of shrinkage ratio for processing 30KhGSA steel with milling. Mechanics and technology. - Taraz: Publishing house "Taraz University" TarSU them. M.H. Dulati, №3- P.36-42.

4. Sherov, K.T. and Mussayev, M.M. (2017). Device for thermal friction cutting of metal workpieces. Patent RK for utility model, No.2165. Bul. №9.

5. Zhunusbekova, Zh.Zh, Kadyrov, A.S. (2016). Study of digging machine flat element loading in clay solution / Journal "Naukovyi Visnyk Natsionalnoho Hirnychoho Universytetu" Volume №2 (152), P.30-33. http://nvngu.in.ua/index.php/ru/component/jdownloads/viewdownload/60/8473

6. Ganyukov, A.A., Kadyrov, A.S., Balabekova, K.G., Kurmasheva, B.K. (2018). Tests and calculations of structural elements of temporary bridges / Roads and Bridges - Drogi i Mosty 17215 - 226. DOI: 10.7409/rabdim.018.014

7. Usubamatov, R., Zain, Z.M., Sin, T.C., Kapaeva, S. (2016). Optimization of multi-tool machining processes with simultaneous action. Int $\mathrm{J}$ Adv Manuf Technol 82, 1227-1239. https://doi.org/10.1007/ s00170-015-6920-x

8. Dudak, N., Taskarina, A., Kasenov, A., Itybaeva, G., Mussina, Z., Abishev, K., Mukanov, R. (2017). Hole Machining Based on Using an Incisive BuiltUp Reamer // International Journal of Precision Engineering and Manufacturing, Volume 18, Issue 10, Pages 1425-1432. https://doi.org/10.1007/s12541017-0170-9 
9. Venkatesan, K. (2017). The study on force, surface integrity, tool life and chip on laser assisted machining of inconel 718 using Nd:YAG laser source, Journal of Advanced Research, Vol.8, pp 407-423. https://doi.org/10.1016/j.jare.2017.05.004

10. Khodzhibergenov, D.T., Esirkepov, A., Sherov, K.T. (2015). Rational milling of metals. Russian Engineering Research. Allerton Press, Inc. Vol. 35. No 1. pp. 43-45. DOI: https://doi.org/10.3103/s1068798 $\mathrm{x} 1501013 \mathrm{x}$

11. Sherov, K.T., Sikhimbayev, M.R., Donenbaev, B.S., Sagitov, A.A., Ainabekova, S.S. (2017). Experimental Research of Rotational-and-Frictional Boring of Big Holes in Large Parts / Journal of Theoretical and Applied Mechanics, Sofia, Vol. 47 No. 4 pp.23-36. https://doi.org/10.1515/jtam-2017-0018

12. Abbas, A.T., Ragab, A.E., Al Bahkali E.A. and El Danaf E.A. (2016). Optimizing Cutting Conditions for Minimum Surface Roughness in Face Milling of High Strength Steel Using Carbide Inserts, Advances in Materials Science and Engineering, Vol.2016, p 14. https://doi.org/10.1155/2016/7372132
13. Kushnazarov, I., Sherov, K. and Altynbaev, R. (2007). Technology of thermal friction milling with high-frequency cooling, High technologies in mechanical engineering: Proc. of scientific works of NTU, Ukraine, P.134-139.

14. Sherov, K.T., Mardonov, B.T., Zharkevich, O.M., Mirgorodskiy, S., Gabdyssalyk, R., Tussupova, S.O., Smakova, N., Akhmedov, Kh.I., Imanbaev, Y.B. (2020). Studying the process of tooling cylindrical gears / Journal of Applied Engineering (JAES) Science, Vol. 18, No. 3 - P. 327-332. https://doi. org/10.5937/jaes18-23794

15. Nasad, T.G., Absadykov, B.N., Tusupova, S.O., Sagitov, A.A., Abdugaliyeva, G.B., Okimbayeva, A.E. (2019). Formation management in parts processing regenerated by surfacing. / News of the Academy of Sciences of the Republic of Kazakhstan, Kazakh national research technical university named after K.I. Satpayev. Series of Geology and technical sciences, №3 (435) - P.102-108. https:// doi.org/10.32014/2019.2518-170x.74 